\title{
Samuel Beckett: escribir (en) el fin ${ }^{1}$ Samuel Beckett: Writing (at) the End
}

\author{
Sergio Rojas \\ Facultad de Artes, Universidad de Chile. Santiago, Chile. \\ sergiorojas_s21@yahoo.com.ar
}

\section{Resumen}

El fin es un motivo que cruza prácticamente toda la obra de Samuel Beckett. En este artículo propongo, con especial atención a su novela Cómo es, que el agotamiento de la significación en la escritura de Beckett no constituye propiamente una tesis o una posición acerca de la "condición humana" (no sirve como ilustración de perspectivas filosóficas de tipo existencialistas), sino que es una exploración de los límites del lenguaje, paradójicamente inagotables.

Palabras clave: Beckett, Cómo es, escritura, fin, silencio.

\section{Abstract}

The end is a motif that crosses practically all of Samuel Beckett's work. In this article I propose, with particular attention to his novel How It Is, that the exhaustion of meaning in Beckett's writing does not properly constitute a thesis or a position about the "human condition" (does not serve as an illustration of existentialist philosophical perspectives), but is an exploration on the limits of language, paradoxically inexhaustible.

Keywords: Beckett, How It Is, writing, end, silence.

1 Proyecto de Investigación Fondecyt Regular n 1151049 (2015-2016): “La ficción del sujeto: el agotamiento del cogito en la escritura de Samuel Beckett”, del cual el autor es Investigador Responsable. 
Me oigo aún murmuro en el lodo

y existo aún

Cómo es, Beckett

Ensayo a continuación una reflexión acerca de la escritura de Samuel Beckett desde la siguiente pregunta: ¿qué sucede cuando se ha llegado al fin? Aunque atiendo aquí especialmente a su novela Cómo es (Comment C'est, 1961 / How It Is, 1964), propongo la cuestión del fin como una clave de lectura de su obra en general. Debo precisar que no es este un estudio monográfico acerca de esta novela, sino que un intento de examinar en Cómo es la cuestión de la escritura del fin (en el fin), que es a la vez el imposible fin de la escritura a partir del momento en que esta ha franqueado el horizonte humanista del sentido (cuando el lenguaje operaba aún como medio de comunicación o como recurso al servicio de la ficción).

\section{La escritura y la ilusión de la comunicación}

En el itinerario que describe la producción de Beckett, esta novela se inscribe en un momento muy especial. En el campo de la narrativa, El Innombrable (1953) lo había sumido -según él mismo señalara- en una "tesitura de grado cero" de la que no podía recuperarse. Pocos años antes, habían aparecido dos de sus obras de teatro más importantes: "Fin de partida" (1957) y "La última cinta de Krapp" (1958). Además, en el mismo año en que aparece Cómo es, se estrena otra de sus piezas de teatro fundamentales: "Días felices" (1961). En todas estas obras son motivos recurrentes la ironía del lenguaje, el paso del tiempo, la identidad del hablante, los afectos pasados y el fin. En cierto modo, casi todos los "temas" que es posible reconocer en su obra implican la reflexión estética y conceptual del fin. Mi hipótesis es que en la novela de 1961 Beckett intenta extremar las posibilidades del lenguaje, más allá del punto al que había llegado en El Innombrable. En el final de esta, sabemos que el innombrable continuará hablando, una vez agotada toda esperanza de poder arribar alguna vez al silencio: "The ending passage of How It Is, as well as those of the earlier The Unnamable, contain the death agonies, but not quite the deaths of the narrators, both breathless, one struggling to crawl while being pulled down by a sea of mud, the other trying to shut out the encroaching silence" (Calder 27).

¿Qué podía significar entonces ir más allá? En sentido estricto, en Cómo es la escritura no da un paso más allá del fin, sino en el fin. Esto se relaciona esencialmente con una determinada idea del fin, que aquí propongo, según la cual este no consiste en el "término" de algo, sino en su agotamiento (el fin es ante todo un proceso). En una carta de 1959, Beckett señala: "Estoy casi siempre en el campo, en el silencio. 
Abandono el teatro y la radio e intento 'continuar' a partir del lugar en que El Innombrable me dejó tirado. No quiere acabar de morirse ni moverse, una situación fascinante" (Konstantinovic 51). Es posible entonces estar en el fin sin haber llegado a término, y es aquí donde surge la cuestión fundamental desde donde leer Cómo es: ¿es concebible un término definitivo para el agotamiento? Años después, escribe en Rumbo a peor (1983): "Lo menos. Lo menos lo mejor lo peor. Lo menos que nunca sea nada. Que nunca llegue a nada. Que nunca lo anule la nada. Inanulable lo menos. Di o mejor peor. A falta de lo peor más peor. Lo menos indisminuible lo mejor peor" (57). ¿Acaso es siempre posible dar un paradójico paso más hacia lo que es menos? Esta no es una cuestión retórica, pues intenta preguntar justamente por aquello que hace posible considerar la obra de Beckett como el itinerario de un trabajo con el lenguaje. El trayecto de su escritura no estaría dado por el tratamiento de determinados temas narrativos, y esto es lo que hace posible hablar de la obra de Beckett, porque el análisis de cada una de sus piezas (narrativas, teatrales, poéticas, ensayísticas, radiofónicas, fílmicas) debe considerar necesariamente, en cada caso, el momento que ella significa en el curso general de su escritura.

Propuse más arriba que la reflexión del fin está comprendida en la mayor parte de la obra de Beckett, por cuanto la interrogante acerca de la naturaleza del fin es inherente a su obsesión por el hecho mismo del lenguaje. En efecto, hay lenguaje, esta es la realidad fundamental en Beckett, y bien podría pensarse que a esto se debe la cotidiana confianza en que es siempre posible la comunicación entre los hombres. Sin embargo, el lenguaje es una realidad tan anterior a todo acto posible con las palabras, que se hace imprescindible interrogar aquella confianza; esto es, si pueden los hombres hacerse efectivamente sujetos del lenguaje y subordinarlo a una voluntad de significación. Por qué se habla, a quién se habla, cómo se habla, incluso quién habla, son cuestiones cuyo sentido implica necesariamente una suerte de cumplimiento relacionado con el lenguaje. Es decir, habría una expectativa operando en todo hecho de lenguaje y es precisamente esta expectativa la que nos remite al fin, como a su cumplimiento o a una definitiva desilusión. ¿Qué expectativa es esta? ¿Qué es lo que se espera por y en el lenguaje? Confiamos en el lenguaje a partir de su "natural" disponibilidad; en efecto, no se echan de menos las palabras cuando creemos de antemano en que es posible alcanzar mediante ellas los objetos y enunciar las tareas que nos hemos propuesto. Conforme a su realidad predada, el lenguaje opera como un medio de comunicación $y$, por lo tanto, la escritura que reflexiona esa prepotente mediación del sentido entre los hombres (haciendo emerger el cuerpo de la comunicación en todas las variantes de su materialidad) cuestiona la expectativa autocumplida de la comunicación. Es más, podría decirse que, al abocarse al lenguaje, Beckett pone al descubierto el simulacro en el que consiste la comunicación.

En el prólogo a la edición española de Film, guion cinematográfico escrito por Beckett en 1963, Jenaro Talens señala que "la escritura beckettiana se esfuerza en neutralizar los significados, ya que los significados no se dejan expulsar. Ese trabajo desde 
la impotencia [...] en busca de lo que no sea polvo (lo nombrable), de lo no-dicho, de lo indecible hace que [la trilogía] esté más cerca de discurso fílmico" (14). Dado que el lenguaje no puede dejar de significar, de lo que se trataría es de "neutralizar los significados”. Pero, ¿para qué? Beckett desarrolla, a su manera, una investigación sobre el lenguaje, por cuanto su escritura es un permanente ejercicio de exploración de sus límites. En el marco de la lectura que propongo, "neutralizar los significados" -tomando la acertada expresión de Talens- consiste en cancelar la ilusión de que el lenguaje ha logrado señalar la realidad, la ilusión de que ha realizado un acto de comunicación.

Lo que resulta más difícil compartir del texto de Talens es su tesis acerca de que habría en la escritura de Beckett un afán emancipador respecto al lenguaje: "la alternativa buscada desesperadamente por la escritura beckettiana: el silencio de lo representado como forma de decirse sin las trampas ni la dominación del lenguaje. Film termina siendo, así, la culminación de la obra de Samuel Beckett” (20). Lo que sucede es que toda su obra consiste más bien en un adentrarse en los recursos de la escritura, y en ese proyecto -si nos es permitido denominarlo así- la desesperación es un recurso, no un pathos subjetivo del que se buscara salir. Si bien es cierto que, como señala Talens, "la obra teatral ha ido buscando la eliminación de cuanto implica relación verbal con la realidad" (18), dicha eliminación es un motivo de su teatro antes que un objetivo formal a conquistar. De hecho, en obras como "La última cinta de Krapp" (1958), "Días felices" (1961), "Play" (1963) o "No Yo" (1972), el lenguaje verbal es el verdadero protagonista.

Entonces, ante ese corto cinematográfico prácticamente mudo que es Film, nos preguntamos: ¿es la muda visualidad del cuerpo aquello hacia lo que se dirige la escritura de Beckett? Más aún, ¿cabe considerar propiamente un tipo de "culminación” en algún momento de su obra? De acuerdo con la tesis del presente artículo, tal cosa no sería posible. Pienso que en Beckett la escritura y el espacio visual del cuerpo (en el teatro o en el cine) corresponden a dos órdenes del lenguaje que son, en más de un punto, radicalmente extraños entre sí. De hecho, el mismo Beckett consideraba al teatro como un descanso de la prosa. Cuando el teatrólogo Michael Haerdter le preguntó qué era el teatro para él, el irlandés respondió: "Para mí el teatro es sobre todo una recreación a partir del trabajo en la novela. Uno cuenta [en el teatro] con un espacio determinado con el que tratar y una serie de personas que pueblan ese espacio. Eso es tranquilizador" (cit. en Cronin 578). Podría decirse que este conjunto de recursos predados descargan al autor, porque contribuyen de alguna manera a determinar el cuerpo de la obra al constituir su ahí. En el teatro, Beckett podía descansar de la tarea de sostener la voz con la escritura, porque es la voz misma la que adquiere materialmente un ahí en ese espacio y con los actores que lo habitan.

Cómo hablar si no es desde el yo, acerca de algo, dirigiéndose hacia alguien, movido por un por qué. El privilegio que parece tener la escritura de la prosa en Beckett se debería a que en esta se hace manifiesta la ficción del sujeto como tal. En la enajenación de la escritura las palabras tienden a diseminarse, y el riesgo de perder su "asunto" -el propio sujeto o sus motivos- es permanente. 
Se escribe en el fin, la ilusión de la comunicación es el espejismo de un contenido trascendente a las palabras. La escisión entre el significante y el significado se corresponde con la del horizonte que separa el arriba en relación con el abajo, el cielo de la tierra, la conciencia respecto del cuerpo, las palabras y las cosas, el amo del esclavo. Como ha señalado Paul Stewart, la figura de la disyunción parece recorrer toda la obra de Beckett, especialmente su narrativa, hasta llegar a Cómo es.

This is/is not quality of the partition can be seen as an extensión of Beckett's common practice of assertion, denial, revision an abandonment throughout his works. How It Is provides the clearest example of this process and on the grandest of scales. All those assumptions which have carried the reader through this difficult novel are eventually denied and abandoned, in as disconcerting a manner as the narrative of Watt reveals its own impossibility (Stewart 148).

En efecto, la disyunción opera estableciendo una distinción entre dos realidades que están intrínsecamente relacionadas entre sí. Considerando esto, podemos conjeturar la que sería una disyunción fundamental en la obra de Beckett, a saber, aquella que distingue entre el orden del sentido humanista de las acciones de sus personajes y el orden de la cotidianeidad concreta en la que existen los individuos (lo que constituye la materia de ese humanismo). No se trata entonces del "sin sentido" de la existencia, sino del modo en que los hombres han debido hacerse en cada caso de un sentido, o al menos pretenderlo (como puede reflexionarse a partir de "Acto sin palabras I"). En su escritura, Beckett reflexiona estéticamente sobre esta disyunción al explorar las aporías de la comunicación.

Relacionada habitualmente con la producción literaria de postguerra en Europa, la obra de Beckett se inscribe, sin duda, en el "contexto" del agotamiento del coeficiente utópico ilustrado de la historia de Occidente. Sin embargo, no encontramos en el autor irlandés una tesis o un diagnóstico acerca de la "condición humana", sino más bien una puesta en obra de la tesitura del fin. Si el hombre ha vivido en la ilusión de la comunicación (con Dios, con sus semejantes, consigo mismo), entonces la pregunta es qué sucederá cuando esa ilusión haya llegado a su fin. El silencio no es sino el fin de la ilusión de la comunicación: "yo en todo caso quiero preguntarle en qué me convierto [what becomes of me] en todo caso cuando el silencio me detiene [...] y en qué voy a convertirme cuando ya no la tenga ["contra mi oreja la voz arrancada por la tortura”] tendré otra cuacua nuestra voz la de todos no dije eso no sabía la mía tampoco" (Cómo es 114).

En Cómo es Beckett intenta detenerse en el fin, es decir: no apresurarse en elaborar teoréticamente una tesis sobre el sin sentido, como si ya se hubiese arribado a un universo de calmada desesperanza. El hombre del siglo xx habita en el fin, diríase que ha construido su frágil cotidianeidad como una precaria costura de la disyunción. Lo que hace Beckett es explorar esa costura, y para esto debe contener el pensamiento en la escritura. 


\section{La falta de fin no se define como absurdo}

La tesis del "absurdo" supone que el lugar del fin de la existencia humana -incluso como lugar de la falta de fin, por lo tanto, del fin como mero lugar- le habría sido manifiesto a la conciencia en el siglo xx. En efecto, esta idea puede sostenerse de modo verosímil y la obra de Beckett no podría "contradecirla" en modo alguno, precisamente porque en esta no encontramos una tesis ni una conclusión; no habría en la escritura de Beckett una idea que proponer respecto a una realidad o a un estado de cosas. $\mathrm{Si}$ la humanidad ha llegado a su fin, ¿qué significa esto en la existencia del individuo? He aquí otra disyunción: humanidad/individuo, porque el agotamiento de aquella se hace sentir en la realidad de este: "se acabó la época de las épocas o solamente de ti no más viajes no más parejas no más abandonos nunca más en ninguna parte oír eso" (Cómo es 30). Acaso la tesis "filosófica" del absurdo sea, después de todo, el consuelo de la conciencia individual que enfrenta un progresivo ya no ante un horizonte que, sin acercarse ni alejarse, comienza simplemente a apagarse, a cerrarse. En una dirección ajena a la tesis del "absurdo", Beckett pone en obra la imposibilidad del fin y, por ende, se desmarca de la impostura que es propia de un pronunciamiento teórico acerca de la condición humana. Su escritura es un permanente deshacerse de toda posición. Lo que queda es poco, un mínimo, detritus. En Beckett nunca hubo sino lo que queda porque nunca se habría hecho sino comenzar. Debido a esto, ese residuo es un mínimo suficiente para iniciar algo, una y otra vez. Siempre se está en el fin porque nunca se ha dejado de comenzar. La incesante repetición del inicio no significa su imposibilidad, sino al contrario: solo hay la necesidad del inicio, solo el inicio es necesario. Esto es lo que ha podido leerse como expresión de una mirada que sanciona el absurdo de la condición humana. Pero la obra de Beckett no solo se diferencia de esa posición teorética, sino que en cierto modo cabe considerarla como su contraparte. La existencia cotidiana se ha dejado constituir en cada momento por un saber que envía a los hombres hacia un lado y otro. La cuestión es en qué consiste ese saber y el lugar del lenguaje en todo ello. Nada más alejado de Beckett que la figura de Sísifo, que vuelve a comenzar una y otra vez, porque el asunto es más bien la imposibilidad de comenzar o, más precisamente, de terminar de comenzar. En 1969 Beckett escribió su pieza "teatral" Aliento (Breath, estrenada en Nueva York el mismo año). La obra tiene una duración de menos de un minuto: enfrentados a una escenografía de basuras escuchamos un lamento débil, una inspiración leve y el primer gemido de un recién nacido, sincronizados estos audios con el incremento y decrecimiento de la luz sobre la escena. Después de unos segundos, cae el telón. No es esta una tesis sobre la existencia, sino una radical operación con el lenguaje en la que, con un mínimo de recursos, se hacen coexistir el inicio y el final hasta casi identificarse.

La imposible consumación del fin es, en Beckett, el hecho del lenguaje. El punto es que efectivamente algo ha sucedido en el itinerario que hace la escritura de Beckett, y es justo en ese acontecimiento donde se encuentra después de El Innombrable. Este 


\section{FIGURA 1}

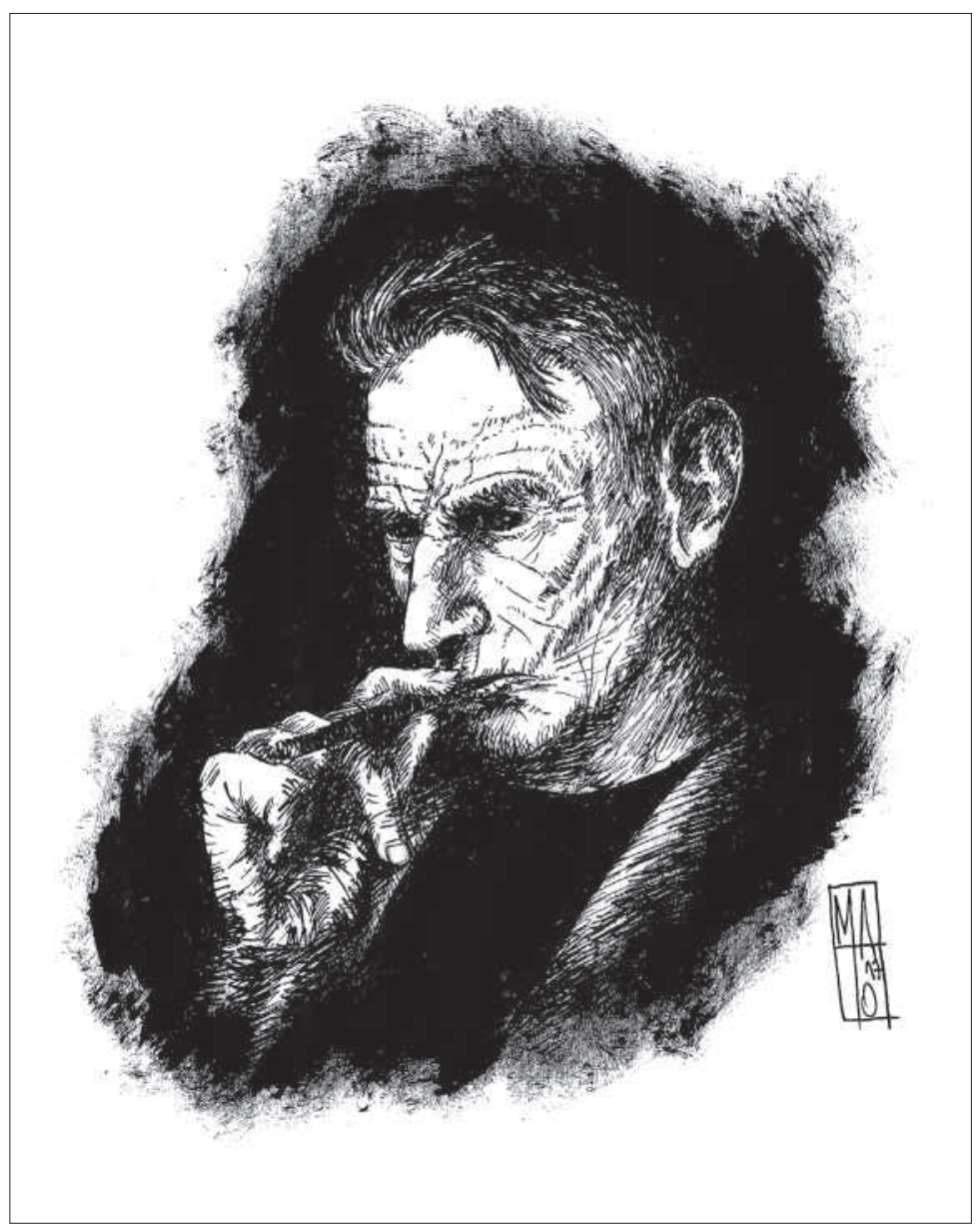

"Samuel Beckett", de Matías Rojas. Dibujo a tinta china sobre papel fabriano.

es el asunto que acomete en la novela que publica ocho años después: Cómo es. En general, es reconocida en la obra de Beckett una poderosa relación entre la situación de inmovilidad de determinados personajes y el silencio. En efecto, la inmovilidad casi absoluta hace que la única acción posible sea el habla, la que se con-funde con el pensamiento del hablante. En su narrativa se hace progresivamente indeterminada la diferencia entre la voz interior y una acción de efectiva comunicación con otra conciencia. Los personajes asisten a su propia habla. Pensar no es otra cosa que oírse hablar, a solas. Pero, a la vez, estar solo es oírse hablar. En relación con esto, en Cómo es resulta fundamental considerar el sentido del fango en el que se encuentran los hablantes y nos recuerda la inmovilidad de Winnie en "Días felices" (1961). Aquí la protagonista, cuyo cuerpo se haya hundido hasta más arriba de la cintura en un 
montículo, rememora su pasado intentando aprender en ello algún tipo de optimismo para enfrentar el presente. También en Cómo es alguien intenta con dificultad rememorar historias pasadas. De eso se pone en antecedentes al lector casi desde el inicio de la novela: "instantes pasados viejos sueños que vuelven o recientes como esos que pasan o algo algo siempre y recuerdos los digo como los oigo los murmuro en el lodo" (9). ¿Qué es aquí el lodo? Si el hablante depende de las palabras para no hundirse del todo, entonces es posible pensar una relación entre las "escenitas" que vienen con las palabras y el lodo que amenaza al hablante como el silencio más absoluto. El lodo es el pasado indiferenciado, extraña fuerza de gravedad que amenaza con disolver la identidad de la voz: "siempre me aferro lo repito al pasado tampoco jamás tendré pasado nunca tuve” (66).

Conforme a nuestra hipótesis de que en Cómo es se trataría de extremar el fin -y, con eso, de dar un paso más allá de El Innombrable-, la indiferente gravedad del lodo en el que se encuentran los personajes nos sugiere la acción del origen en el fin: "tibieza de barro original oscuridad impenetrable" (14). El lodo es mudo, y es precisamente flotando en esa mudez que el hablante se mueve, manteniéndose en la superficie mediante las palabras: "las palabras tienen su utilidad el lodo es mudo" (32). Porque darse un pasado es una forma de darse un comienzo y también un futuro, una historia al fin. La voz dice: "todo el pasado está en el pasado" (75). Podría pensarse que el lodo es ese pasado indiferenciado que se sustrae a las palabras. Pero también es posible que ese pasado, mi pasado, haya desaparecido en las voces de los otros, en las palabras de otros: "en mí los que estuvieron fuera cuando termine ese jadeo restos de una voz antigua que no es la mía" (9). Entonces el lodo no sería sino una espesura infinitamente profunda hecha de palabras, donde la identidad ha naufragado. Deshabitadas por la conciencia, las palabras no se hacen oír. Imposible no pensar aquí en la situación del personaje en "La última cinta de Krapp", quien escucha en viejas cintas magnetofónicas su voz diseminada como si fuese la voz de otro; o, más precisamente, haciéndose consciente, en medio del silencio, de ese otro en el que se convirtió al cabo de los años, alguien ya sin voz propia. Krapp es el ahí de esa conciencia que ha llegado a carecer de palabras propias. El personaje es, como sugerí anteriormente, el recurso límite que presta el teatro a Beckett. En cambio, en Cómo es la ficción de la identidad, o incluso de la conciencia que persiste enmudecida por hablas ajenas, ha desaparecido. Dese una cierta lectura, Cómo es finaliza con una multitud de criaturas reuniéndose todas ellas en la singularidad de una voz. Peter Boxal pone en cuestión esa interpretación: "But the result of this concentration into homogeneity is the production of extraordinarily persistent forms of dissonance and difference that refuse to be bound, and that open up new tears in the word Surface" (46). En efecto, la cuestión no es saber finalmente cuántos hablan, sino atender a lo que vibra en esa pluralidad de voces: "esta voz estas voces cómo saber si no es un coro una sola pero cuacua quiere decir por todas partes megáfonos la técnica posible pero atención" (Cómo es 130). La representación deviene al cabo una visualidad imposible. 
En cierto sentido, Cómo es consiste en una novela sobre el amor, pero lo es también acerca de la imposibilidad del amor y, especialmente, de la imposibilidad de contar una historia. La figura de la observación cruza toda la novela y la escritura parece por momentos corresponder a un dictado: la voz del narrador relata las historias del otro. La autoconciencia, operación moderna de soberanía y autarquía, deviene con Beckett en un acto de alienante pérdida de sí. Es indudable el coeficiente filosófico de esta cuestión. La conciencia requiere necesariamente de una forma de autoconciencia para tomarse a sí misma por asunto, para ocuparse de sus percepciones, recuerdos, emociones, etcétera. Pero, ¿cómo podría esta conciencia de segundo orden saber de sí, no hundirse en la nada, si no surge otra conciencia por sobre ella?: "en realidad todos estamos desde el impensable primero hasta el no menos impensable último pegados unos con otros en una imbricación de carnes sin fisura [in a vast imbrication of flesh without breach or fissure]" (Cómo es 172). Escribir es como obedecer a un dictado; entrometerse hasta tornar audible, traducir y editar el habla pura de un otro. Entonces, quien ejecuta el "dictado" debe editar la locura de ese otro que habla (que habla para si), tornar coherente esa manera otra de usar las palabras, siempre otra porque solo habla para sí misma.

En Cómo es la diferencia de la autoconciencia alojada en la escritura parece haber llegado a su fin. Intermitentemente la escritura está aquí atravesada por la invención de otro, en un débil pero sostenido intento por recuperar la diferencia. La lectura de Cómo es nos hace presente el "cierre" de El innombrable. En este la voz dice, ya cerca de la última página, "es menester, en mis viejas historias llegadas de no sé dónde, intentar descubrir la suya, que ha de estar, que debió ser la mía, antes de ser la suya" (El Innombrable 181). Reconocíamos todavía aquí la cuestión de la identidad de la voz como un asunto gravitante. En Cómo es, en cambio, se trata del movimiento mismo por el cual la conciencia del hablante se pierde y se recompone sin solución de continuidad: "ya no digo quien habla ya no se dice no debe tener importancia" (26). Emerge entonces la pregunta acerca de qué significa en la escritura de Beckett seguir hablando más allá del fin. Acaso ya no sea posible leer El Innombrable sin iniciar la lectura de Cómo es, en la imposibilidad de decidir tanto el final de la primera como el inicio de la segunda. Dada la imposibilidad de detenerse, y en la conciencia de que aún estoy aquí, acaece la única certeza, la que parece abrir el porvenir antes que cerrarlo, pero como un porvenir de lo mismo: la certeza de que sólo hay palabras: "algunas viejas palabras de vez en cuando juntar unas con otras hacer frases" (Cómo es 129). He aquí la fatigosa exigencia a la que es sometido el lector de Cómo es. La escritura de Beckett ha ingresado en un flujo de conciencia en el que la identidad, esa que depende de lograr atrapar y contar una historia de ese pasado (conciencia que se hace sujeto rememorando un fragmento del pasado como propio), se pierde constantemente a sí misma. La disyunción ha dejado de ser un asunto, un tema, un motivo todavía literario, y es ahora una operación en que la conciencia del hablante extravía su identidad: "falta de atención de memoria los tiempos que se mezclan 
en mi cabeza todos los tiempos antes durante después de tiempos enormes" (130). Nunca se insistirá lo suficiente en que esta novela carece por completo de un asunto narrativo; es más, en sentido estricto se podría decir que no es una novela, sino más bien una especie de "ya no" de la novela. Y digo que nunca se insistirá lo suficiente en ello porque su lectura se ejerce performáticamente desde el como si de la novela, esto es, desde el simulacro de una narración en curso, intentando con ello satisfacer la expectativa que es propia de la lectura concreta.

¿Qué es lo que hace máximamente difícil -acaso imposible- la lectura de Cómo es? Se trata de un texto astillado, como si las palabras de la novela no hubiesen sido escritas en la página por un autor, sino que más bien flotaran en ella como los restos de un naufragio. En El Innombrable todavía sucedía algo, el habla se conducía hacia el fin, era el proceso de la pregunta por quién habla la que al cabo quedará sin respuesta. De ahí que en Beckett el fin corresponda a la figura del aún-no, pues el camino se acaba cuando todavía nada ha sido dicho. Olga Bernal sostiene que Cómo es corresponde al final de un itinerario iniciado en Murphy (1938):

Para llegar a Cómo es [...], era preciso remontar el camino del lenguaje, destruir los rastros por él dejados. Este camino de olvido consta de cinco etapas, etapas constituidas por las cinco novelas anteriores a Cómo es. Entre cada una de estas obras media una distancia recorrida, y una etapa de 'des-construcción' superada. Estas etapas consisten en el progresivo abandono de la representación (177).

¿En qué consiste esta progresión y en qué sentido esta encontraría en Cómo es su mayor radicalidad? Según Bernal, la escritura de Beckett finaliza aquí el "desmoronamiento de las formas"; sin embargo, se trata de "un desmoronamiento tan incoercible, que este mismo exige el acceso a la representación" (177). Es decir, no se abandona simplemente el territorio de la representación, sino que esta dejará su lugar, precisamente como lugar de la falta: una obra abandonada. Anticipa de alguna manera aquello que en Rumbo a peor se dice: "Huecos para cuando se vayan las palabras" (71). Entonces, como sugería anteriormente, Cómo es no se deja leer como una novela, pero no es otra cosa que una novela; es, de hecho, el lugar de una novela, y es también la imposibilidad de la novela. En su ensayo sobre la trilogía beckettiana, Rolf Breuer sostiene que es propio de la literatura autorreflexiva el desgaste que la conduciría hacia su propia imposibilidad: "la novela se ha convertido en ensayo sobre la novela y más exactamente (dado que se trata de un objetivo negativo) la novela es un ensayo sobre el dejar de escribir novelas. Sin duda es un broche lógico para el principio de la autorreflexividad en la literatura" (132). Ahora bien, lo singular de la escritura de Beckett es que no solo nos conduce hacia el límite del "desgaste", sino que -tal es mi hipótesis en este artículo- plantea la cuestión de la frontera última de agotamiento: ¿es posible dar un paso más? Esta es la cuestión fundamental, donde la literatura es la ocasión para el desarrollo de la escritura. No se trata de dar un paso más allá del desgaste, en la perspectiva de algo así como un nuevo inicio, sino de abundar en el agotamiento 
mismo. Beckett escribió Cómo es con plena conciencia de que se trataba de una de sus obras más difíciles, acaso de una obra imposible. James Knowlson comenta que el escritor no llegaba a trabajar en ella más de dos o tres horas al día: "a dozen lines a day were an achievement; half a page almost a triumph" (461).

\section{El fin de la interpretación}

En sentido estricto, no es posible la lectura de Cómo es porque no es posible seguir un curso de sentido en el encabalgamiento significante. Su fragmentariedad la diferencia radicalmente de la escritura de la trilogía; podría decirse que el fragmento desplaza a la noción de detritus o residuo: "The epoch of the comma is followed, most notably in How It Is and the 'cylinder pieces' and short residua of the 1960s and 1970s, by a suppression of all punctuation but the full stop (not even this is available in How It Is), accompanied progressively by the withering away of predicative forms" (Connor 124).

La dificultad con la que se encuentra el lector de Cómo es no se refiere solo a la comprensión de sentido, sino que se hace sentir en el ejercicio concreto de su lectura. Así como la voz en El Innombrable seguirá hablando aun cuando ya no sea posible decir algo (porque no es posible dejar de hablar si se comenzó a hacerlo sin motivo), así también, de forma análoga, no nos es dada la posibilidad de abandonar la lectura de Cómo es, porque no hemos ingresado en el curso de una historia que, en algún momento, pudiera parecernos "incongruente" o "falta de asunto". El hecho fundamental en la obra de Beckett no es propiamente el habla, sino la imposibilidad de dejar de hablar; más precisamente, la imposibilidad de contener el habla. Un pensamiento que está hecho de palabras se despliega dando lugar en su "performance" al efecto de una contención originaria que, por lo mismo, comienza a expresarse al modo en que algo se desencadena, como en una demasía. En Cómo es no asistimos en modo alguno a la exposición de un supuesto "contenido" que hubiese estado como reservado desde el comienzo, sino al infinito agotamiento de ese intento por decirlo todo. Y allí, en donde el lector quisiera representarse a un sujeto que balbucea, lo que acontece más bien es la disolución de ese supuesto sujeto: "silencios cada vez más largos tiempos enormes pérdidas cada vez mayores él [Pim] de respuestas yo de preguntas" (91). Lo que está sucediendo es, pues, tremendo. Pero no se trata de un acontecimiento que el lenguaje pudiera significar al modo en que se refiere algo trascendente, porque es el lenguaje mismo lo que ha sido llevado a la situación de un acontecimiento. Aunque la escritura de Beckett no es filosófica, se desarrolla en un campo minado por problemas filosóficos. "Al ser un escritor oscuro y presuntamente profundo, también él [como Joyce] revestía un atractivo evidente para la crítica expositiva de corte académico" (Cronin 503). En efecto, la crítica en general, al hacer de esa escritura su objeto, la transforma en una cifrada reflexión sobre el lenguaje. 
De ahí la vorágine de interpretaciones a la que ha dado lugar la obra de Beckett. En 1967 John Calder vaticinaba: "Se han escrito más libros sobre Jesucristo, Napoleón y Wagner, en este orden, que sobre nadie. Predigo que en el año 2000 Beckett puede ser el cuarto de la lista si el diluvio actual de literatura beckettiana continúa" (cit. en Rodríguez 8). Es como si el juicio sobre su obra oscilara entre, de una parte, el ejercicio inagotable de interpretaciones por parte del pensamiento teórico especulativo y, por otra, la percepción de que su obra se deja conducir hacia la simple falta de asunto. Para el lector es un problema leer una obra que le impide ocupar cómodamente su lugar. Habría que tomar muy en serio el impulso que durante la "lectura" empuja al lector a abandonar el libro, especialmente si, habiendo llegado a la mitad de la novela, no siente que esté efectivamente en la mitad de algo. Cuando en 1982 el escritor Seamus Heaney le preguntó a Borges: “¿Qué opina de Beckett, tal vez el discípulo literario irlandés más cercano a Joyce?”, el escritor argentino respondió: “Samuel Beckett es muy aburrido. Vi su obra Esperando a Godot y eso me bastó. Me pareció que era una obra muy pobre. ¿Para qué tomarse la molestia de esperar a Godot si él nunca llega? Qué cosa tan tediosa. Después de eso, ya no tuve deseos de leer sus novelas" (cit. en Heaney). En el simple comentario de Borges queda presentado el problema: ¿qué sentido tiene la espera de algo que no llega?

La cuestión recién señalada podría dar cuenta tanto del interés hermenéutico que sigue generando la obra de Beckett, como también del desinterés o decepción que provoca en muchos lectores y espectadores. Porque no se trataría solo de interpretar la espera (concepto que sintetiza los motivos de la búsqueda, de la interrogación permanente, del relato que prolifera sin tema central, de la escucha prolongada, etcétera) o el que nada se cumple en ella, sino del hecho de que los personajes permanecen ahí, incluso cuando las expectativas ya han muerto definitivamente. Beckett intenta dar con ese hecho en el lenguaje (en el habla y en la escucha), como algo que, paradójicamente, orienta su escritura hacia una especie de "más allá" de las palabras. Porque no hay palabras disponibles para referir el hecho de que la espera misma -ese mientras que se prolonga más allá de todo entendimiento y voluntad- está hecha de lenguaje, concretamente de palabras.

En Textos para nada, Beckett conjetura lo que habría de ser el desenlace imposible para una espera que nunca desespera: "Y habrá un día aquí, donde no hay días, aquí que no es un lugar, originado por la imposible voz el infactible ser, y un comienzo de día, en que todo será silencioso y vacío y oscuridad, como ahora, como pronto cuando todo haya acabado, cuando todo esté dicho, dice ella, murmura" (125). En Cómo es la escritura de Beckett ensaya plegarse a la tesitura de un "alguien" que sigue hablando y escuchando en el final. Pero, ¿qué podría decirse u oírse en el final? ¿Cómo podría haber palabras en el final? El final parece, con todo, impensable sin palabras, sin paisaje. La escritura tendría entonces que poner en obra la negación, plegarse sobre sí misma. En el breve escrito "Sans" ("Sin”, según la excelente traducción de Félix de Azúa), asistimos a una especie de no-paisaje: “Tierra arena mismo gris que el aire el 
cielo el cuerpo las ruinas arena fina gris ceniza. Luz refugio blancor raso rostros sin trazo ningún recuerdo. Infinito sin relieve cuerpo pequeño solo en pie mismo gris en todo tierra cielo cuerpo ruinas" (184). Podría decirse "lo mínimo", sin embargo, pienso que la expresión más adecuada sería lo menos: una visión que no llega a fijarse en una representación porque siempre podría ser menos, infinitamente menos. En inglés el título de este relato es Lessness, una palabra elaborada por el mismo Beckett. Al respecto, Cioran escribió:

La palabra Lessness (tan insondable como el Ungrud de Boehme) me hechizó de tal manera que una noche le dije a Beckett que no me acostaría sin haberle encontrado un equivalente honorable en francés. Habíamos estado examinando todas las formas posibles sugeridas por sans y moindre. Ninguna nos había parecido acercarse al inagotable Lessness, mezcla de privación y de infinito, vacuidad sinónimo de apoteosis. Nos separamos aquella noche decepcionados (Cioran 51).

El relato, como varias de sus obras, parece ofrecerse al propósito de interpretarlo a la vez que, paradójicamente, es refractario a toda especulación en torno a su sentido, porque Beckett está ante todo haciendo algo con las palabras, y no transmitiendo un contenido ideológico.

Frank Kermode sanciona negativamente las novelas que Beckett supuestamente escribió teniendo como uno de sus objetivos precisamente imposibilitar la interpretación: "Podemos sospechar que buena parte del éxito de estos libros [Malone muere, Molloy, El Innombrable] se debe a su determinación de esquivar la interpretación. En buena medida, se trata de novelas fallidas, debo ser franco en este punto, pues los hombres de letras estamos demasiado dispuestos a asumir la voluntad del escritor" (124).

Cabe preguntarse, sin embargo, ¿cuál era la voluntad de Beckett como escritor? Anthony Cronin, quien en su momento comentó muy positivamente la publicación de Cómo es, posteriormente también toma distancia de esta novela e incluso de su propio entusiasmo inicial:

me inquieta mi propio entusiasmo por esta última 'novela' [How It Is] u obra en
prosa de cierta extensión; creo que debería haber insinuado que Beckett [...] tal
vez había llegado a un punto, en lo tocante al menos a sus prosas largas, en el que
las satisfacciones estéticas, las bellezas incidentales de la sonoridad y del sentido,
e incluso el esclarecimiento de la existencia humana, parecían insuficiente recom-
pensa a cambio de las penurias y dificultades que se exigía al lector soportar (549).

Pienso que ese punto al que había llegado Beckett en Cómo es consistía en avanzar entre las palabras sin otro recurso que las preguntas que el hecho mismo del lenguaje le provocaba, las que, en cualquier caso, planteaban la cuestión del límite. No se trataba, por lo tanto, de un intento por "esclarecer la existencia humana", sino de explorar ese 
coeficiente inagotable de trascendencia que radica en las palabras, incluso más intensamente manifiesto cuando las palabras se aproximaban a un mínimo (de significación, de volumen, de enunciación). El punto es que, precisamente a partir de ese irreductible mínimo hacia el que se dirige la escritura de Beckett, es posible, en cierto modo, reflexionar la cuestión del sentido de la existencia humana. Pero, como ya hemos señalado en este artículo, no era ese el objetivo de Beckett. Acaso el comentario de Cronin recién citado sea acertado, pero en un sentido distinto al del autor. Es imposible leer Cómo es esperando un "esclarecimiento de la existencia humana". Sin embargo, difícilmente esta obra podría leerse, en el momento de su aparición, sin esa expectativa, y por lo tanto debía acontecer todavía un tramo importante en la historia de la literatura para que otra lectura fuese posible. Como ha señalado acertadamente Anthony Uhlmann: "How It Is is one of Beckett's more challenging works and, no doubt as a consequence, it has not yet been fully understood. This in turn means that the current generation of critics are beginning to turn more attention towards it" (106). Fernando de Toro ha cuestionado explícitamente la lectura filosófica que Ulmhann hace de la obra de Beckett, pues juzga errado el supuesto de que la obra de este sea "filosófica": "encuentro cuestionable el caracterizar su obra como filosófica, puesto que, si este hubiera sido su propósito, entonces habría escrito filosofía y no "literatura"' (223). Sin embargo, no es en absoluto errado reconocer en una obra literaria una dimensión filosófica, precisamente allí en donde el pensamiento avanza sin hacer de la escritura un objeto sobre el cual aplicar categorías ya ganadas en otro lugar (la literatura como mera ilustración de la filosofía), sino dejándose interpelar. El mismo de Toro entiende así la lectura que se propone hacer de Beckett: "deseo dejar que el texto(s) me hable(en), esto es, hacer una lectura hermenéutica en el sentido filosófico de esta actividad, una lectura íntima, cercana, siguiendo la práctica de lectura que Derrida nos enseñó” (218).

\section{No puede terminar lo que no ha podido comenzar}

En la segunda parte de Cómo es se describen las acciones que alguien (o algo) realiza intentando comunicarse con otro a través de su cuerpo. Las acciones están destinadas ante todo a producir dolor, mediante el cual quien está siendo torturado tendría noticias de un único "mensaje": hay alguien intentando comunicarse. Hacer "saber" eso consiste en penetrar ese cuerpo. No es posible saber con claridad cuántos cuerpos hay en la novela. Por momentos, la lectura nos sugiere que, tal vez, solo exista una conciencia -una voz: "llega tendré una voz no hay más voz en el mundo que la mía un murmullo tenido una vida allá arriba" (Cómo es 93)-, intentando dar con la existencia de alguien más, con otra conciencia. Pero, ¿cómo dar con ese otro si no es a través de la materia del cuerpo? Cómo comunicar a otro la propia existencia, cuando soy la demanda de otra conciencia, soy la necesidad de hacerme saber a mí mismo en otro. El equívoco interpretativo consiste en identificar una conciencia con 
una voz, como si a cada conciencia le fuese dada la posibilidad de reconocer $s u$ voz. No hay tal correspondencia.

¿Qué es "la vida allá arriba"? La identidad de Pim se confunde con la del hablante, como si este debiese hablar de otro para poder hablar de sí. Se habla desde el lodo acerca de "arriba". Pero nunca habría existido sino una voz, la voz de todos: "aquí no hay sino una forma de hablar uno tras otro [...] la voz habla como nosotros la nuestra de todos" (94). Entonces la cuestión es cómo adquieren una identidad de conciencia los hablantes, cómo establecer una diferencia en el flujo de habla -de la escritura- cuando hablan como arrebatándose el micrófono (como sucede en la obra "Play [Comedie]", de 1963). En su excelente libro sobre la presencia de la filosofía de Arnold Geulincx en la obra de Beckett, David Tucker señala: "In contrast to the number of studies citing Dante's relations to this novel, Geulincx's name has never been invoked in relation to the mud of Comment c'est / How It Is" (156). En sus años de estudiante, Beckett manifestó gran interés por el pensamiento de Arnold Geulincx (1624-1669), discípulo de Descartes (fue de hecho quien introdujo a Descartes en Holanda). El principio de Geulincx: Ubi nihil vales, ibi nihil velis, expresa en cierto modo la actitud ante la vida de varios de los personajes beckettianos: "donde nada vales, nada quieras"; la existencia se define por la operación de un repliegue del yo sobre sí mismo, desde un mundo que parece no responder pregunta alguna ni corresponder a ninguna expectativa. Según Geulincx, el hombre es solo un espectador de su existencia, pues el verdadero agente es Dios; así, queda el hombre sumido en una especie de ocasionalismo radical, pues nunca llegará a comprender las causas de sus propios actos. Es en este sentido que Tucker afirma que el barro en Cómo es tiene un "Geuligian aspect" (156). Hacia el final de la novela leemos: "no hay respuesta las tinieblas no hay respuesta ya no turbar el silencio no hay respuesta morir no hay respuesta MORIR aullidos PODRÉ MORIR aullidos VOY A MORIR aullidos bueno" (Cómo es 181).

El problema fundamental no es la conquista de la autoconciencia, sino más bien de la identidad. La autoconciencia se proyecta al infinito, en el efecto especular conocido como "puesta en abismo": "rumor transmisible al infinito en ambas direcciones" (Cómo es 147). Autoconciencia e identidad se tensionan entonces en Beckett, por cuanto la primera consiste en el vértigo de una absoluta transparencia, sin ningún tipo de opacidad. En esta "puesta en abismo", no se trata solo de un observador instalado sobre otro, el que a su vez también observa, sino también de un hablante que oye voces o de escribientes a la escucha -a la espera- de una voz propia. La pregunta "cómo es" tiene el sentido de un "cómo era". En el pasado de las palabras dichas, existe un alguien, en tramas de lenguaje tejidas por quienes estaban allí, hablando de él o como asuntos de su propio murmullo interior, siempre volcado hacia afuera. Escribe Tucker: "He must defer to this other, just Beckett's narrator requires a narrated, because there is no such thing as director knowledge or unmediated experience, no event in the present or memory of the past that does not elude one as one tries 'to grasp it"' (158). 
La idea de que habría en el comienzo un habla contenida se relaciona con la imagen que tiene Beckett de sí mismo, como la de alguien que nació muerto o que lleva en su interior un no-nacido, que por lo tanto no ha podido aún comenzar a hablar. La lectura de Beckett también nos sugiere una relación entre este inquietante presentimiento de haber nacido muerto y la imagen de haber nacido anciano: "esta infancia que yo habría tenido la dificultad de creer en ella la impresión de haber nacido más bien octogenario a la edad en que se muere en tinieblas" (Cómo es 87). Es decir, de haber nacido cuando ya no quedaba esperanza. La imagen del niño que existe muerto es recurrente en Beckett. En Textos para nada escribe: "Aquí se celebrará mañana el concilio, rezarán por mi alma, como por la de un muerto, como por la de un niño muerto, dentro de su madre muerta, para que no vaya al limbo, es bonita, la teología" (98). Entonces, se ha comenzado a hablar cuando ya era demasiado tarde, porque no se trata de decir algo en especial, ni tampoco de decirlo todo, sino de decir algo que no esté ya perdido: “y siempre la misma cosa las mismas cosas posibles imposibles o yo que sólo me doy cuenta cuando termina ese jadeo que no oigo sino eso las mismas cosas cuatro cinco algunos adornos la vida allá arriba escenitas" (Cómo es 130-31).

La escritura de Beckett no es "filosófica", si se habría de entender por esto el que comprenda una tesis, no es la prueba de una hipótesis, ni tampoco ensaya una respuesta estética a alguna cuestión teorética. Sin embargo, como señalé casi al inicio de este artículo, complejas y exigentes cuestiones filosóficas se encuentran en su obra, como si se tratara ante todo de hacer ingresar en el lenguaje la dificultad misma de tales cuestiones. Ha tomado cuerpo en la escritura de Beckett la dificultad de "la filosofía", pero en modo alguno la disciplina de las respuestas. En sus obras, Beckett no ha querido responder sino preguntar, y entonces resultaría tan impertinente interrogarlo acerca de qué ha querido preguntar como acerca de sus supuestas "respuestas" a la existencia. El mismo Beckett se quejaba al respecto: “¿Cuándo dejarán de hacerme querer decir más de lo que digo?”, le comenta al escritor Raymond Federman (cit. en Rodríguez 12). Y respecto a "Fin de partida", una de las obras que más producción crítica ha provocado, Beckett escribe: "no pretende ser más que una pieza. Nada menos. Nada tiene que ver por lo tanto con interrogantes y respuestas. Para tales menesteres existen universidades, iglesias, cafeterías, etc." (Disjecta 126). Sin embargo, es indudable la inagotable fascinación especulativa que, más allá de la estética, ejerce su obra. Se trata, en efecto, de una escritura completamente refractaria a la teoría, pero lo es de tal manera que la exige en todo momento como su otro.

Dos formas de silencio coexisten en la obra de Beckett. Primero, el silencio que permite escuchar la voz de ese otro que habla en la soledad del ego. El silencio opera aquí como una apertura que es a la vez una escisión entre el yo que habla y el que escucha. Silencio del medium. La otra forma del silencio en su obra es aquella que da a pensar el fin: las palabras son trascendentes al mundo que nombran, parecen desde ya anunciar que seguirán siempre allí, cuando ya no quede nada ni nadie ni por qué 
nombrar. Este permanecer de las palabras que seguirán siendo dichas es lo que en Beckett permite -incluso exige- pensar el fin como aquello que no habrá de consumarse. Tal vez porque es el hecho mismo del lenguaje, la materialidad de las palabras, lo que enajena al sujeto, que pareciera estar siempre llegando a las palabras -necesitándolasdesde otro lugar. El "yo" ha llegado al lenguaje para recién saber acerca de su propia existencia. Fernando de Toro afirma que Beckett "liquida toda noción de representación, al menos como esta se ha entendido desde Aristóteles hasta el fin de la Modernidad que Beckett, como Cage en música o Pollock en pintura, se encarga de obliterar" (231). En efecto, es posible decir que Cage y Pollock, como también Duchamp, obliteran la modernidad, pero esto no significa necesariamente que la cancelen, mucho menos que la "superen" (expresión esta cargada de modernidad), sino que operan en el fin de la representación y, de esa manera, en el fin del sujeto. La experiencia del mundo ya no está formalizada a priori por una estructura o condiciones de tipo kantiano; al contrario, a partir de la historia material e intelectual del siglo $\mathrm{xx}$, es la experiencia misma -no "la realidad"- lo que excede la posibilidad de comprensión. El hombre habría llegado a no ser contemporáneo de su propia experiencia. La escritura de Beckett acontece en las ruinas del sujeto -no en su simple ausencia-.

La cuestión del fin en Beckett implica el problema del origen del sujeto, como origen desde siempre diferido. Entonces, en el ya no del fin resuena necesariamente el aún no del inicio; de ahí que en Beckett la imposibilidad de terminar(se) sea la imposibilidad de comenzar(se).

\section{Referencias}

Breuer, Rolf. "La autorreflexividad en la literatura ejemplificada en la trilogía novelística de Samuel Beckett”. La realidad inventada. ¿Cómo sabemos lo que creemos saber? Comp. Paul Watzlawick. Barcelona, Gedisa, 1990, pp. 121-138.

Beckett, Samuel. How It Is. Nueva York, Grove Press, 1964.

---. Cómo es. Trad. José Emilio Pacheco. México, Editorial Joaquín Moritz, 1966.

---. El Innombrable. Trad. R. Santos Torroella. Madrid, Alianza, 1979.

---. “Sin”. Trad. Félix de Azúa. Relatos. Barcelona, Tusquets, 1997, pp. 183-187.

---. Textos para nada. Trad. Ana María Moix. Relatos. Barcelona, Tusquets, 1997, pp. 81-125.

---. Rumbo a peor. Trad. L. Aguilera, D. Aguirre, G. Dols, R. Falcó y M. MartínezLange. Barcelona, Lumen, 2001.

---. Disjecta. Escritos misceláneos y un fragmento dramático. Trad. Alicia Martínez Yuste. Madrid, Arena Libros, 2009.

Bernal, Olga. Lenguaje y ficción en las novelas de Beckett. Barcelona, Lumen, 1969.

Calder, John. The Philosophy of Samuel Beckett. Londres, Calder Publications/Riverrun Press, 2001. 
Cioran, E. M. "Encuentros con Beckett”. Revista de la Universidad de México, n 472, 1990, pp. 51-53, http://www.revistadelauniversidad.unam.mx/ojs_rum/index. $\mathrm{php} / \mathrm{rum} / \mathrm{article} / \mathrm{view} / 13183 / 14421$

Connor, Steven. Beckett, Modernism and the Material Imagination. Nueva York, Cambridge University Press, 2014.

Cronin, Anthony. Samuel Beckett. El último modernista. Segovia, Ediciones La Uña Rota, 2012.

De Toro, Fernando. "Samuel Beckett, El Innombrable y el fin de la modernidad", EPOS. Revista de Filología, n² 26, 2010, http://revistas.uned.es/index.php/ EPOS/article/view/10644

Heaney, Seamus. “Un diálogo entre Jorge Luis Borges y Seamus Heaney”. 1981, http:// www.galeon.com/literarias/borges.htm

Kermode, Frank. "Beckett, Snow y la pobreza pura (en torno Samuel Beckett)”. El leve ruido del piso de arriba. Textos críticos sobre escritores contemporáneos. Santiago de Chile, Universidad Diego Portales, 2014, pp. 117-127.

Knowlson, James. Damned to Fame. The Life of Samuel Beckett. Londres, Bloomsbury, 1997. Konstantinovic, Radomir. Beckett, mi amigo. Barcelona, Littera, 2001.

Rodríguez Gago, Antonia. "Introducción a Los días felices de Samuel Beckett”. Espapdf. com, 2016, http://assets.espapdf.com/b/Samuel\%20Beckett/Losdiasfelices\%20 (5878)/Los\%20dias\%20felices\%20-\%20Samuel\%20Beckett.pdf

Stewart, Paul. Zone of Evaporation: Samuel Beckett's Disjunctions. Amsterdam/Nueva York, Rodopi, 2006.

Talens, Jenaro. “A propósito de Film”. Film. Trad. Jenaro Talens. Barcelona, Tusquets, 2001.

Tucker, David. Samuel Beckett and Arnold Geulincx. Tracing 'A literary fantasia'. Londres, Continuum, 2012.

Uhlmann, Anthony. “Beckett's Intertexts”. Samuel Beckett, Ed. Dirk van Hulle. Cambridge, Cambridge University Press, 2015, pp. 103-113.

Enviado: 10 julio 2017

Aceptado: 16 abril 2018 